\title{
EFFECTS OF HYPOXIA AND HYPERCAPNIA ON PERCEPTION OF THERMAL CUTANEOUS PAIN
}

\author{
By J. STOKES, III, W. P. CHAPMAN, AND L. H. SMITH ${ }^{1}$ \\ (From the Department of Physiology, Harvard Medical School, Boston)
}

(Received for publication June 20, 1947)

Asphyxia, which combines depletion of oxygen (hypoxia) with accumulation of carbon dioxide (hypercapnia), is known to modify sensation. While prolonged, mild hypoxia impairs vision and certain other sensations (1), its effect on the perception of thermal pain has not been described. Similarly, severe hypercapnia produced by breathing 30 per cent carbon dioxide produces anesthesia $(2,3)$, but the analgetic effects of lower concentrations have received only brief consideration $(4,5)$. The present studies were undertaken to determine whether hypoxia or hypercapnia is responsible for the analgesia of asphyxia. The results led secondarily to a comparison of carbon dioxide and nitrous oxide with respect to their quantitative effects on pain perception and their site of action.

\section{SUBJECTS AND METHOD}

Observations were made on 14 healthy male subjects between the ages of 20 and 45 years. Eleven were medical students, and three were members of the teaching staff.

Apparatus and methods were quite similar to those described by Hardy, Wolff, and Goodell (6) except for two minor modifications of technique. Stimuli, consisting of graded radiant heat, from a 1000-watt bulb and lens, previously calibrated by a radiometer, were applied for exactly three seconds to 3.5 square centimeters of blackened skin on the forehead and in some experiments on the forearm. "Threshold for pain" was taken as the lowest rate of heating, expressed in $\mathrm{gm}$. cal. per $\mathrm{cm}^{2}$ per sec., which produced a clear, "sticking" pain, i.e., a sensation of sharp, needle-like penetration into the skin, as described by Chapman and Jones (7).

Two slight modifications were introduced $(a)$ because of the rapid changes in blood gases produced by modifying the composition of inspired air, and $(b)$ because it was necessary to measure changes in threshold quickly to avoid unduly prolonged exposure to abnormal gas mixtures. Stimuli were, therefore, applied for three seconds out of each 30 seconds instead of each one or two minutes as advised when more slowly developing changes are followed, e.g., effects of drugs. For reasons described below it was found very important under these conditions to

1 Student Research Fellow, Life Insurance Medical Research Fund. prevent local ischemia. Therefore, the exposed skin rested against a radially ridged celluloid plate, rather than immediately against the edges of the aperture itself.

Gas mixtures were prepared in a bank of Tissot recording spirometers (capacity of each 100 liters) from which the subject breathed out to the atmosphere. A three-way valve permitted shifting from one mixture to another without the knowledge of the subject. The mouthpiece and nose-clip were carefully adjusted to avoid discomfort. Arterial blood pressure, heart rate, respiratory minute volume and respiratory rate were recorded during the observations on hypoxia and hypercapnia.

\section{OBSERVATIONS}

\section{The effect of local ischemia and its avoidance}

The necessity in these observations of determining changes in threshold rapidly has been mentioned. As illustrated in Figure 1 (left) stimuli were applied every 30 seconds and reported by the subject as "clear sticking pain" (solid dots), "doubtful" (half shaded circles) and "not painful" (open circles). The intensity of stimulus was changed frequently so that the accuracy of each threshold stimulus was verified by one or more sub-threshold stimuli in close proximity. In Figure 1 (left) all the readings taken are included to show general procedure, but in other charts only the threshold values themselves are given. In this manner five or more verified determinations of threshold could usually be obtained in $71 / 2$ minutes as shown by the solid dots connected by solid lines.

Control observations with such stimulation every 30 seconds yielded results which were at first considerably more variable than those described for stimulation every one to two minutes. This variability appeared to be related in part to the degree of firmness with which the subject pressed his forehead against the edges of the aperture. As shown in Figure 1 (left) the threshold observed when the forehead was resting lightly against the head rest was measurably higher than when the subject purposely held his forehead in place with 


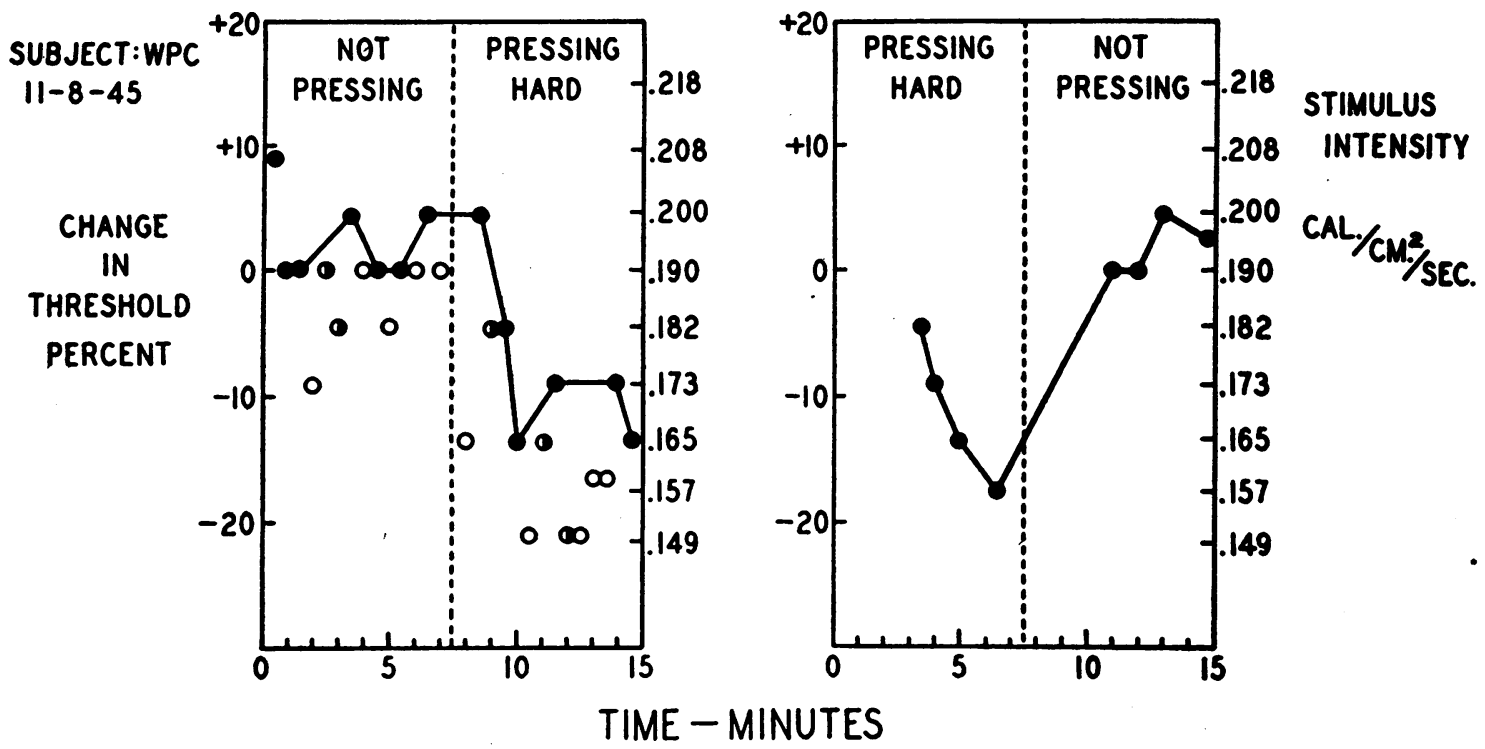

Fig. 1. Chart Showing Effect on Threshold of Pressing forehead Firmly Against the Aperture to Produce Local Ischemia

To the left all responses are charted to show subthreshold (open circles and half open circles) and threshold responses (dots). To the right, as in all subsequent charts, only threshold responses are charted.

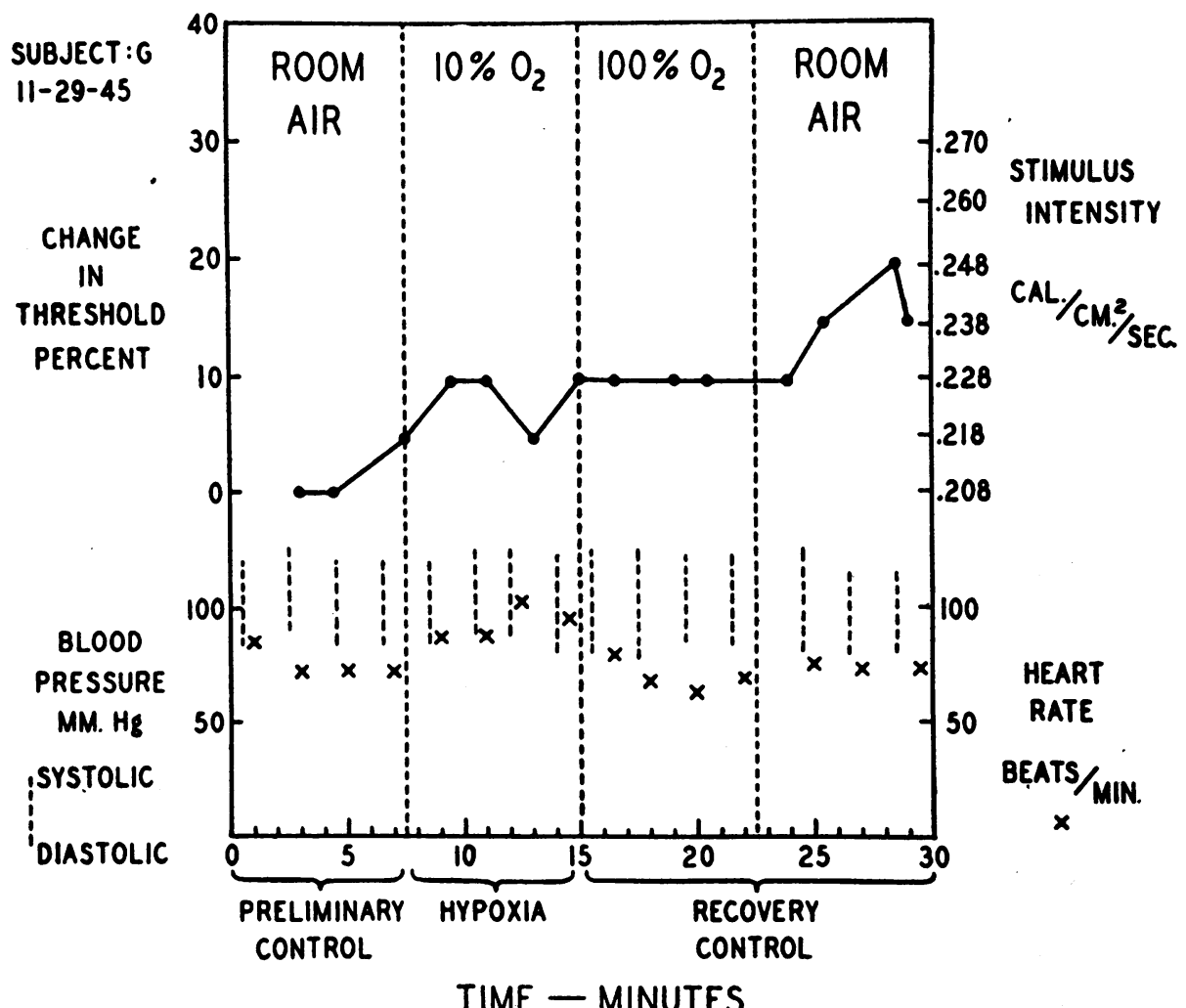

Fig. 2. Chart Showing Absence of Significant Change in Pain Threshold During Acute Anoxia 
firm, but not painful, pressure. An observation in reverse order is shown to the right of Figure 1.

It is a common observation that water at $44.5^{\circ}$ C. is usually not painful to the extremities when circulation is normal but may become intolerably painful when circulation is arrested and convection of heat by blood thereby eliminated. Therefore it seemed likely that pressing the skin of the forehead against the edge of the aperture might, particularly in the mid-line, produce local ischemia and thereby change threshold. In addition, stimulation at intervals of 30 seconds afforded less opportunity for interim cooling by radiation and air convection than is provided by conventional stimulation every one or two minutes.

Lewis and Pochin (8) showed that prolonged local asphyxia is required to modify several types of cutaneous pain sensation, the late changes being a diminution and loss in pain sense. With heat, however, Bigelow et al. (9; see Figure 3, p. 507) observed in the forearm first a fall in threshold for both burning pain and pricking pain followed after 10 to 20 minutes by analgesia. Likewise, in our experiments local interference with circulation was associated with a reduction of pain threshold (Figure 1). This observation was verified by other studies on the forearm (Figure 4) in which painless arrest of blood flow with a pneumatic cuff on the upper arm reduced threshold by 20 per cent. In repeated thermal stimulation of one skin area the effect of local ischemia on pain threshold must be due in part to reduced dissipation of heat by the circulation, but the simultaneous effect of local asphyxia of the stimulated nerve endings may also play a role (9).

Whenever the forehead was used, errors from this "ischemia artefact" were avoided by placing around the aperture a circle of celluloid with six radiating spokes $2 \mathrm{~mm}$. high. Pressing the forehead firmly, but painlessly, against these supports did not affect threshold presumably because blood continued to flow through blood vessels between the spokes, and interim cooling was more effective. Even when this artefact was excluded thresholds were still not entirely constant because most subjects showed some adaptation to repeated thermal stimulation, both acutely and chronically. In each series of 60 exposures (compare initial and terminal control periods in Figures 2, 3 and 4) threshold rose slowly and by varying amounts. Repeated experiments once or twice weekly on the same subjects over a period of five weeks also revealed a slow rise of threshold averaging less than 15 per cent. This slow adaptation did not affect perceptibly the acute changes produced by experimental procedures. It could not be eliminated but it was controlled by keeping the total number of exposures constant for each observation.

\section{The effects of hypoxia}

Figure 2 illustrates a typical experiment in which the subject breathed $(a)$ room air for a control period of 7.5 minutes, (b) 10 per cent oxygen in nitrogen for 7.5 minutes, (c) 100 per cent oxygen for a like period and finally room air again for a terminal control period. The results in a total of six subjects are summarized in Table I.

TABLE I

Comparison of the effects produced by hypoxia, hypercapnia, voluntary hyperventilation and nitrous oxide

\begin{tabular}{l|c|c|c|c|c}
\hline & \multicolumn{3}{|c|}{ Average percentage increase of } \\
\cline { 3 - 6 } Procedure & $\begin{array}{c}\text { Num- } \\
\text { ber of } \\
\text { sub- } \\
\text { jects }\end{array}$ & $\begin{array}{c}\text { Heart } \\
\text { rate }\end{array}$ & $\begin{array}{c}\text { Blood } \\
\text { pressure, } \\
\text { syst./diast. }\end{array}$ & $\begin{array}{c}\text { Min- } \\
\text { ute } \\
\text { vol- } \\
\text { ume }\end{array}$ & $\begin{array}{c}\text { Pain } \\
\text { thresh- } \\
\text { old }\end{array}$ \\
\hline $\begin{array}{l}\text { Hypoxia } \\
10 \% \mathrm{O}_{2} \text { in } \mathrm{N}_{2}\end{array}$ & 6 & 26 & $0 / 0$ & 37 & 0 \\
$\begin{array}{l}\mathrm{Hypercapnia} \\
5 \% \mathrm{CO}_{2} \text { in } \mathrm{O}_{2}\end{array}$ & 9 & 6 & $15 / 9$ & 280 & 13 \\
$7.5 \% \mathrm{CO}_{2}$ in $\mathrm{O}_{2}$ & 9 & 13 & $23 / 21$ & 380 & 28 \\
$\begin{array}{l}\text { Voluntary } \\
\text { hyperventilation }\end{array}$ & 2 & 12 & $4 / 0$ & 310 & 4 \\
Room air & 4 & & & & 27 \\
$30 \% \mathrm{~N}_{2} \mathrm{O}$ in $\mathrm{O}_{2}$ & 4 & & &
\end{tabular}

Anoxia sufficient to increase heart rate by an average of 26 per cent and ventilation by an average of 37 per cent had no significant effect on threshold for thermal pain.

Figure 2 shows also the apparent fluctuations in threshold which demonstrate the subject's inability to differentiate between changes of stimulus intensity amounting to less than 5 per cent. The gradual rise in threshold is characteristic of adaptation and not related to the period of hypoxia. It appears, therefore, that hypoxia affects pain sensation far less than certain other sensations, e.g., vision (10). 


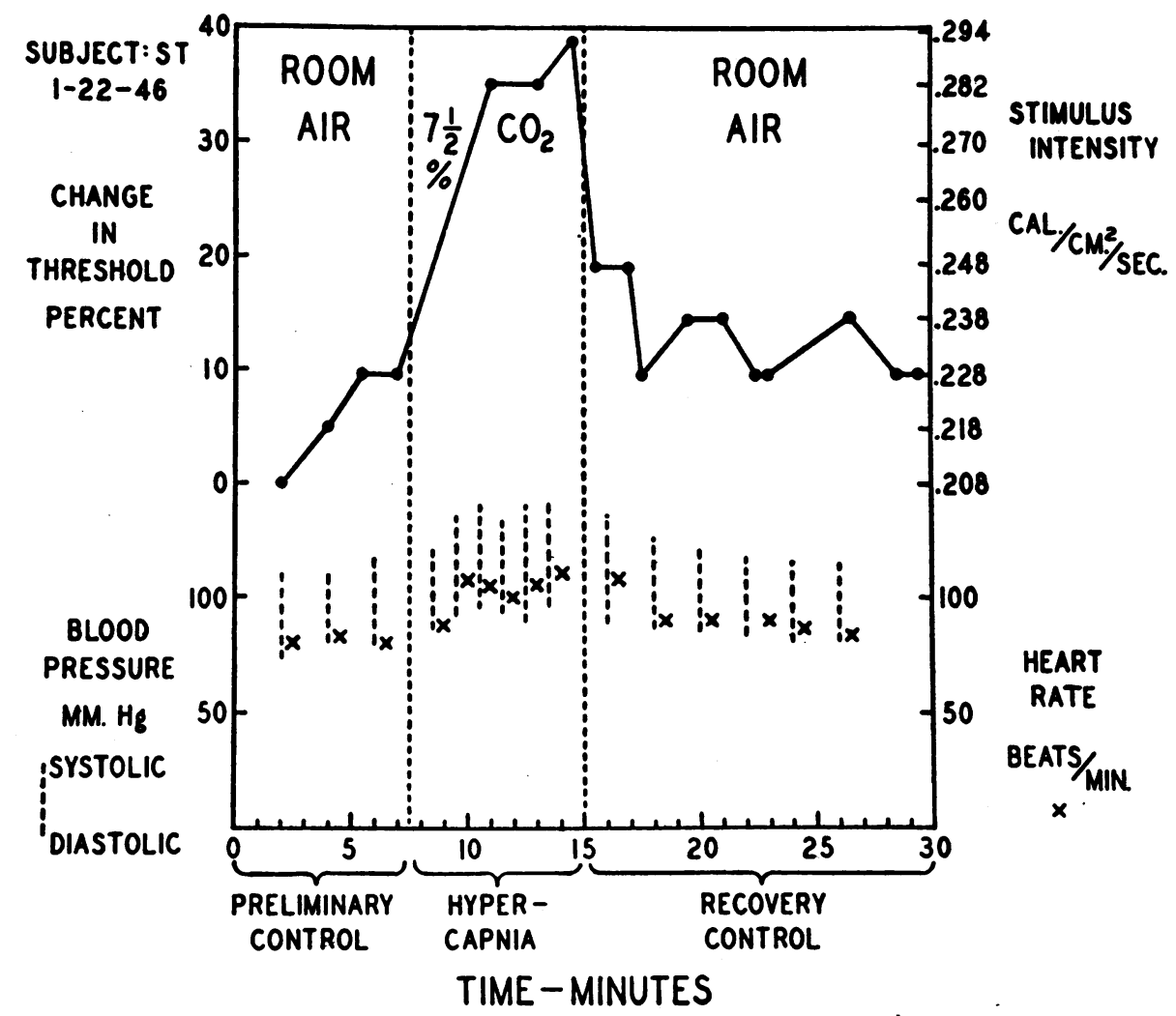

Fig. 3. Chart Showing the Effrect on Pain Threshold of Breathing 7.5 Per Cent Carbon Dioxide for 7.5 Minutes

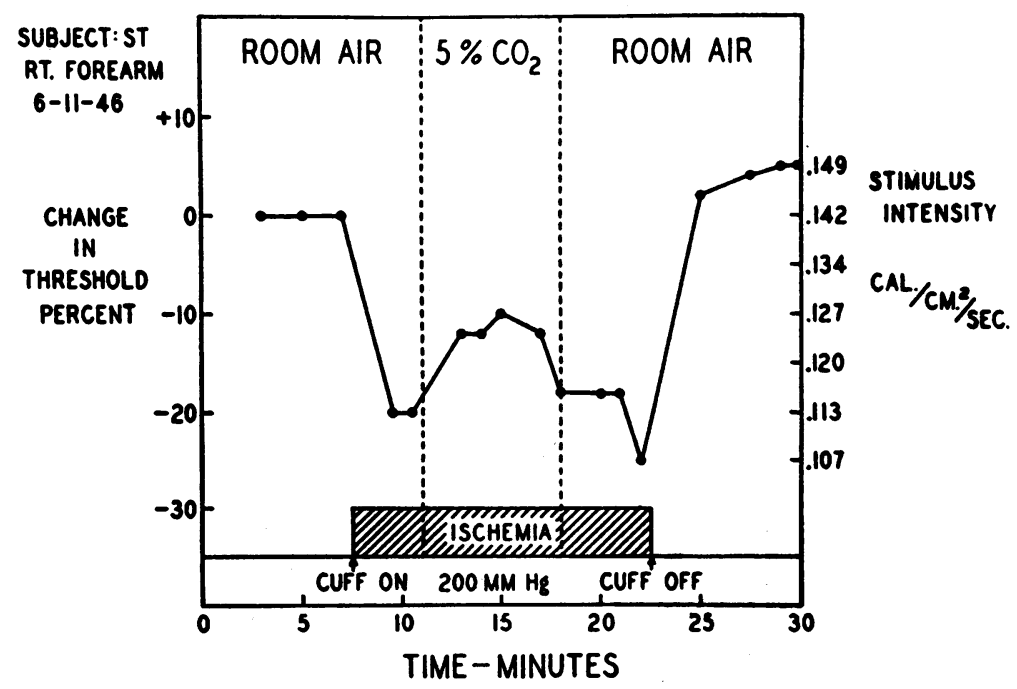

Fig. 4. Chart Showing (a) The Decrease in Threshold in the Forearm Produced by Arresting Blood Flow and (b) the Rise of Threshold Produced During this Ischemia by Inhaling Carbon Dioxide

This indicates that carbon dioxide produces analgesia by central action rather than by direct effect on peripheral pain receptors. 


\section{The effects of hypercapnia}

In striking contrast to hypoxia, moderate hypercapnia produced by breathing mixtures of 5 and 7.5 per cent $\mathrm{CO}_{2}$ elevated threshold significantly in all subjects. The response of subject ST to 7.5 per cent $\mathrm{CO}_{2}$ is shown in Figure 3 and the data on nine subjects are averaged in Table $\mathrm{I}$. In each subject threshold rose abruptly by at least 9 per cent while 5 per cent $\mathrm{CO}_{2}$ was breathed and by at least 18 per cent while 7.5 per cent $\mathrm{CO}_{2}$ was breathed. The average effects were a 13 per cent and a 28 per cent rise in threshold, respectively. Simultaneously blood pressure and heart rate increased moderately while minute volume rose markedly.

Before concluding that the rise in threshold was due solely to a direct analgetic effect of $\mathrm{CO}_{2}$ it was necessary to exclude the possibility that other physiological responses to hypercapnia were involved. (a) The mild to moderate sweating, which hypercapnia produces, can be excluded because it has been shown that profuse sweating does not influence the threshold for thermal pain (7). (b) Though breathing carbon dioxide produces vasodilatation in the finger tips (11) blood flow to the skin of the forehead is not likely to be affected by inhalation of carbon dioxide because flow is always rapid and not subject to vasoconstrictor influences. The breathing of carbon dioxide did not change skin temperature of the forehead measured by thermocouple in experiments similar to those in Figure 3 except for omitting the intermittent application of radiant heat. (c) Though several subjects mentioned the distraction and mild discomfort experienced during the period of hyperpnea, voluntary hyperventilation to match the hyperpnea produced by $\mathrm{CO}_{2}$ did not affect threshold significantly (Table I). It may be concluded that carbon dioxide can produce specific analgesia and that in early asphyxia pain sensation is affected more by the accumulation of carbon dioxide than by depletion of oxygen.

\section{The central vs. the peripheral action of carbon dioxide}

Carbon dioxide might conceivably produce its effects either by acting upon sensory end organs in the skin, or upon more centrally located parts of the nervous system. In order to distinguish be- tween these two possibilities an area of skin on the flexor surface of the forearm was blackened and exposed to heat stimuli ( $a$ ) with normal circulation, (b) during total occlusion of blood flow by inflating a pneumatic cuff on the upper arm to $250 \mathrm{~mm}$. $\mathrm{Hg}$ and then (c) with added inhalation of 5 per cent $\mathrm{CO}_{2}$. This procedure permitted the inhaled $\mathrm{CO}_{2}$ to reach the central nervous system but not the end organs in the ischemic forearm. It has already been mentioned that very prolonged ischemia is necessary to change pain sensation by direct action on peripheral receptors (8).

Figure 4 illustrates the type of response observed in three subjects. Superimposed upon the fall in threshold to be expected from arrest of blood flow (see also Figure 1), the inhalation of 5 per cent $\mathrm{CO}_{2}$ produced the usual rise of threshold. Shifting the subject to room air permitted threshold to fall again to the level characteristic of ischemia alone and restoring blood flow elevated the threshold to normal. This indicates that the analgetic effect of carbon dioxide is not peripheral, but chiefly central.

\section{DISCUSSION}

It is interesting to compare the side effects of carbon dioxide with those of intermediate concentrations of nitrous oxide which are known to be definitely analgetic. (12). In three subjects 30 per cent nitrous oxide elevated threshold by an average of 27 per cent in agreement with previous work (12). While breathing this concentration of nitrous oxide subjects described euphoria, dissociation with their surroundings and ringing in the ears. Inhalation of 7.5 per cent $\mathrm{CO}_{2}$ elevated threshold by a similar amount, 28 per cent, but the sensations were otherwise limited to the increase in respiratory movement with transient headache in some instances during or immediately following the experiment. Additional studies, similar to those illustrated in Figure 4, showed that nitrous oxide, like $\mathrm{CO}_{2}$, produces analgesia by central, rather than peripheral, action.

\section{SUM MARY}

Threshold for thermal pain was determined in healthy male subjects during moderate hypoxia and hypercapnia. An "artefact" from ischemia is described. This consists of a lowering of threshhold which is produced when arrest of circulation 
interferes with the convection of heat away from the stimulated area by blood flow and with blood supply to the pain endings in the area being tested. It is particularly important when stimuli are repeated at short intervals.

Breathing 10 per cent oxygen did not affect pain threshold significantly while 5 and 7.5 per cent carbon dioxide elevated threshold by an average of 13 to 28 per cent, respectively. These effects were found to be due to central action rather than to any peripheral effect on the pain end organs. Nitrous oxide in 30 per cent concentration affected pain threshold similarly and also acted centrally.

The analgesia of early asphyxia appears to be due to the central action of accumulated carbon dioxide, not to lowering of oxygen tension, though the latter in sufficient grade is known to produce disorientation and sudden unconsciousness eventually.

\section{BIBLIOGRAPHY}

1. McFarland, R. A., The psychological effects of oxygen deprivation (anoxemia) on human behavior. Archives of Psychol., Columbia Univ., 1932, 145, 5.

2. Leake, C. D., and Waters, R. M., The anesthetic properties of carbon dioxide. Anesth. \& Analg., 1929, 8, 17.

3. Seevers, M. H., The narcotic properties of carbon dioxide. New York State J. Med., 1944, 44, 597.
4. Brown, E. W., The physiological effects of high concentrations of carbon dioxide. U. S. Naval M. Bull., 1930, 28, 721.

5. Kleindorfer, G. B., The effect of carbon dioxide on ether, ethylene, and nitrous oxide anesthesia. J. Pharmacol. \& Exper. Therap., 1931, 43, 445.

6. Hardy, J. D., Wolff, H. G., and Goodell, H., Studies on pain; new method for measuring pain threshold: observations on spatial summation of pain. J. Clin. Invest., 1940, 19, 649.

7. Chapman, W. P., and Jones, C. M., Variations in cutaneous and visceral pain sensitivity in normal subjects. J. Clin. Invest., 1944, 23, 81.

8. Lewis, T., and Pochin, E. E., Effects of asphyxia and pressure on sensory nerves of man. Clin. Sc., 1938, 3, 141.

9. Bigelow, N., Harrison, I., Goodell, H., and Wolff, H. G., Quantitative measurements of two pain sensations of the skin, with reference to the nature of the "hyperalgesia of peripheral neuritis." J. Clin. Invest., 1945, 24, 503.

10. McFarland, R. A., and Evans, J. N., Alterations in dark adaptation under reduced oxygen tensions. Am. J. Physiol., 1939, 127, 37.

11. Engineering Memorandum No. 10CR, The Effect of Inhaling Carbon Dioxide on Digital Skin Temperature. Climatic Research Unit, Fort Monmouth, N. J., 1944.

12. Chapman, W. P., Arrowood, J. G., and Beecher, H. K., The analgetic effects of low concentrations of nitrous oxide compared in man with morphine sulphate. J. Clin. Invest., 1943, 22, 871. 